\title{
Experimental Investigations on Stir Cast Aluminium with addition of vanadium pentoxide powders
}

\author{
T. Vijaya Kumar ${ }^{1}$, B.V.Dharmendra ${ }^{2}$, M.Nageswara Rao $^{3}$, Dollu.Bhaskar ${ }^{4}$, K.V.Ramana ${ }^{5}$ \\ ${ }^{1}$ Assoc.Professor, Department of Mechanical Engg., Koneru Lakshmaiah Education Foundation, Deemed to be \\ University, Green Fields, Vaddeswaram, Guntur-522 502, India, vijay_mech@ kluniversity.in \\ ${ }^{2}$ Professor, Department of Mechanical Engg., Koneru Lakshmaiah Education Foundation, Deemed to be University, \\ Green Fields, Vaddeswaram, Guntur-522 502, India, dharmbv@kluniversity.in \\ Assoc.Professor, Department of Mechanical Engg., Koneru Lakshmaiah Education Foundation, Deemed to be \\ University, Green Fields, Vaddeswaram, Guntur-522 502, India, medikondu@kluniversity.in \\ ${ }^{4}$ Asst.Professor, Department of Mechanical Engg., Koneru Lakshmaiah Education Foundation, Deemed to be \\ University, Green Fields, Vaddeswaram, Guntur-522 502, India, dbhhaskarr@kluniversity.in \\ ${ }^{5}$ Professor, Department of Mechanical Engg., Koneru Lakshmaiah Education Foundation, Deemed to be University, \\ Green Fields, Vaddeswaram, Guntur-522 502, India, proframana@ kluniversity.in
}

\begin{abstract}
Metal matrix composites (MMC) have become attractive for structural engineering applications due to their excellent unique strength properties and are increasingly seen as alternatives to traditional materials, especially in the automotive, aerospace and defence industries. $\mathrm{Al}-\mathrm{V}_{2} \mathrm{O}_{5}$ MMC's has aluminium as matrix and particles of vandium pentoxide as reinforcements and exhibits many mechanical properties that are attractive. In the present work, an attempt was made by stir casting technique to produce $\mathrm{Al}-\mathrm{V}_{2} \mathrm{O}_{5}$ composite as it homogeneously distributes the reinforcement in the matrix with no interfacial chemical reaction. $\mathrm{V}_{2} \mathrm{O}_{5}$ particles containing different weight fractions (5\% and 10\%) is used as reinforcement. The paper presents the processing of $\mathrm{Al}-\mathrm{V}_{2} \mathrm{O}_{5}$ by the Stir cast method to achieve the desired properties, as well as the findings of the experimental analysis of the mechanical properties of $\mathrm{Al}-\mathrm{V}_{2} \mathrm{O}_{5}$.

Key words: $\mathrm{MMC}, \mathrm{V}_{2} \mathrm{O}_{5}$, Stir casting, Hardness test,
\end{abstract} Impact test, Bending test.

\section{INTRODUCTION}

Metal matrix composites (MMC's) are propelled design materials created by a mixture of atleast two materials in which desired properties are achieved. Designing MMC's consisting of irregular fibres or particles in metal for amalgamation having a mixture of properties which are not feasible in solid materials. These properties may combine high explicit consistency, machinability, reduction of wear and low coefficient of thermal expansion. Metal Matrix Composites are metals reinforced with other metals, ceramic or organic compounds. They are rendered by dispersing the reinforcements of the metal matrix. Strengthening is typically performed to strengthen the properties of base metal, such as weight, stiffness, etc. Aluminium and its alloys attracted the most interest as the base metal in metal matrix composites. Aluminium MMCs are commonly used in aircraft, automobiles and other areas[1]. The reinforcements should be stable and non-reactive at the required working temperature. The reinforcements most widely used are Silicon Carbide $(\mathrm{SiC})$ and Aluminium Oxide $\left(\mathrm{Al}_{2} \mathrm{O}_{3}\right)$. $\mathrm{SiC}$ reinforcement improves the tensile strength, hardness, density and wear resistance of Aluminium and its alloys. Particle distribution plays a very important role in the properties of the Al-MMC which is strengthened by strong shearing [2].

\section{EXPERIMENTATION}

\subsection{Materials Used}

For the preparation of metal matrix composite, Aluminium is the base material and Vanadium Pentoxide $\left(\mathrm{V}_{2} \mathrm{O}_{5}\right)$ is selected as reinforcement[3]. The detailed composition of the composite is, as mentioned in Table 1.

Table 1: Chemical Constitution of $\mathrm{Al}-\mathrm{V}_{2} \mathrm{O}_{5}$ Composites

\begin{tabular}{|c|l|c|}
\hline S.No. & \multicolumn{1}{|c|}{ Composition } & Weight (\%) \\
\hline 1 & PureAluminium $(\mathrm{Al})$ & $100 \%$ \\
\hline 2 & PureAluminum $+\mathrm{V}_{2} \mathrm{O}_{5}$ & $95 \%+5 \%$ \\
\hline 3 & PureAluminum $+\mathrm{V}_{2} \mathrm{O}_{5}$ & $90 \%+10 \%$ \\
\hline
\end{tabular}




\subsection{Preparation of Composites (MMC's)}

The composite metal matrix was produced using the most economical process known as Stir Casting or Vortex technique. Pure Aluminium ingot is taken as the matrix material in the present work and vanadium pentoxide as a reinforcement. To start with, the casting of pure aluminium is manufactured. For that reason, the appropriate $2 \mathrm{~kg}$ pure aluminium ingot is measured and placed in a muffle furnace inside the graphite crucible present. The furnace temperature is set at $675{ }^{\circ} \mathrm{C}$, regulated by the digital temperature control system[4]. After reaching that temperature, the molten $\mathrm{Al}$ formed is poured into a cylindrical cast iron mould with a diameter of $200 \mathrm{~mm}$ x $20 \mathrm{~mm}$ and then, after a few minutes, the mould is unfastened and the solidified $\mathrm{Al}$ castings are removed. The $\mathrm{Al}$ ingot is now placed in a graphite crucible at a temperature of $700{ }^{0} \mathrm{C}$ for composite preparation (95 percent $\mathrm{Al}+5$ percent $\mathrm{V}_{2} \mathrm{O}_{5}$ ) and the $\mathrm{V}_{2} \mathrm{O}_{5}$ reinforcement added is $5 \mathrm{wt}$ percent in the vortex produced by a mechanical stirring assisted by a variable speed motor. The stirring shall be carried out in order to achieve a standardized mixture of two contents in the slurry[5]. The speed of the stirrer is controlled using the speed controller and its rpm maintained is 250 . The rotation is sustained for around 5 minutes. Argon is used at a pressure of 10 bar to preserve inertness. Then the molten composite is transferred to the appropriate cylindrical mould. In 10 minutes, the casting solidifies[6]. After that, the 90 percent $\mathrm{Al}$ and 10 percent $\mathrm{V}_{2} \mathrm{O}_{5}$ castings are prepared using the same technique and the temperature of the furnace is set at $750^{\circ} \mathrm{C}$. Figure. 1 represents equipment used for Stir Casting and castings obtained in the mould.
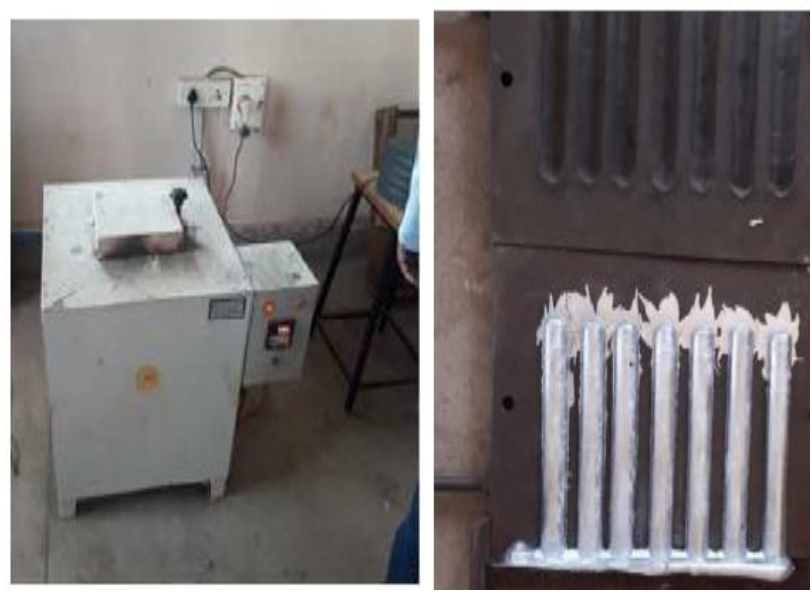

Figure 1: Equipment Used for Stir Casting and Castings Obtained in the Mould

\subsection{Testing of Specimens}

Once the composites were prepared, impact test, bending test and hardness test were performed. For all these tests, the specimens had different dimensions.

\subsubsection{Rockwell Hardness Test}

The Rockwell test evaluating the significance of passage of an indenter underneath an enormous weight appeared differently in relation to the penetration made by a preload (minor weight). The output is always a dimensionless amount expressed as HRA, HRB, HRC. The spot the rest of the letter is the character Rockwell scale[7]. For hardness test, the composites had the dimension of $25 \mathrm{~mm}$ on each side i.e. length, breadth and height. The hardness estimation is finished utilizing the Rockwell hardness analyzer. The sample models are determined to a metal iron square and displayed into closeness with a minimum weight (Ten kilograms), that as analyzing plastic materials is a solid steel ball. This shape the ground indented to "B." The dial is varied as per minimum value under the application of minimum weight applied and the total weight is left (sixty or one hundred kilograms), that makes the ball indent into the model of plastic test giving away the indented surface "D." After that, following an extra fifteen seconds (may be an aggregate of thirty seconds), the examination of hardness is done on the dial with minimum weight although all the things applied and surface yields "R". Figure. 2 represents Rockwell hardness test equipment.

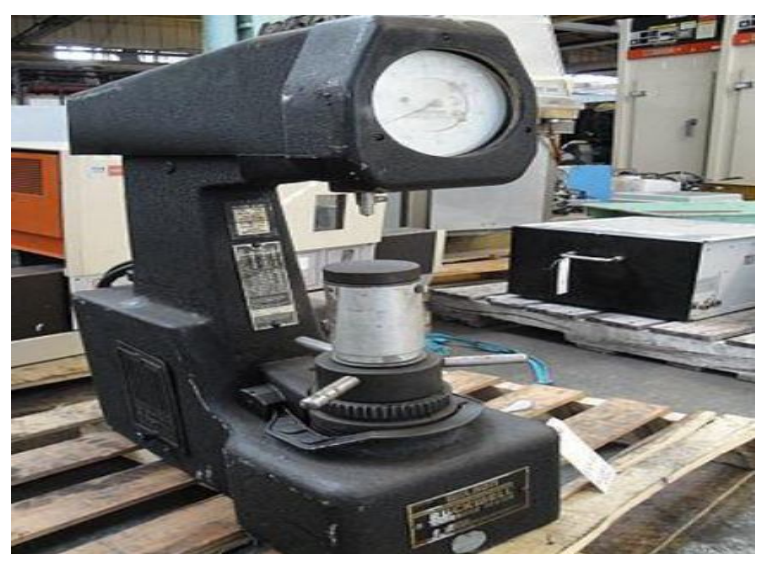

Figure 2: Rockwell hardness tester

\subsubsection{Impact Test}

Charpy Impact test is for toughness and sensitivity of the notch and is measured by finding the amount of energy absorbed by the material during fracturing, typically for metals, ceramics, composites, polymers. Brittle materials absorb little energy, while ductile 
materials absorb more energy for fractures as well. Test values are determined by dividing the fracture energy with the cross-section area of the specimen. Before the impact test, the specimens are prepared from the form of the cylinder to the square rods $(10 \mathrm{~mm} \times 10 \mathrm{~mm}$ X $55 \mathrm{~mm})$ by milling. The 'U' notch is made of a saw up to $2 \mathrm{~mm}$ deep in the middle of the rod. Initially the specimen shall be made with a size of $10 \mathrm{~mm}$ X $10 \mathrm{~mm}$ X $55 \mathrm{~mm}$; the notch shall be made at the exact middle of the specimen[8]. The pendulum is held at its highest location and the impact without the specimen is measured to detect the initial impact from the scale given, which could be caused by friction in the machine. After that, this specimen is positioned in the striking edge support so that the ' $U$ ' notch is in the direction of the test unit. Figure. 3 shows impact testing machine.

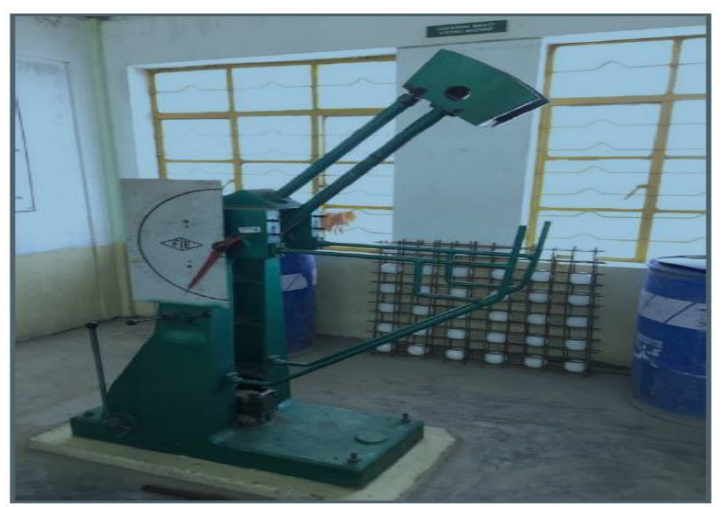

Figure 3: Charpy Impact testing machine

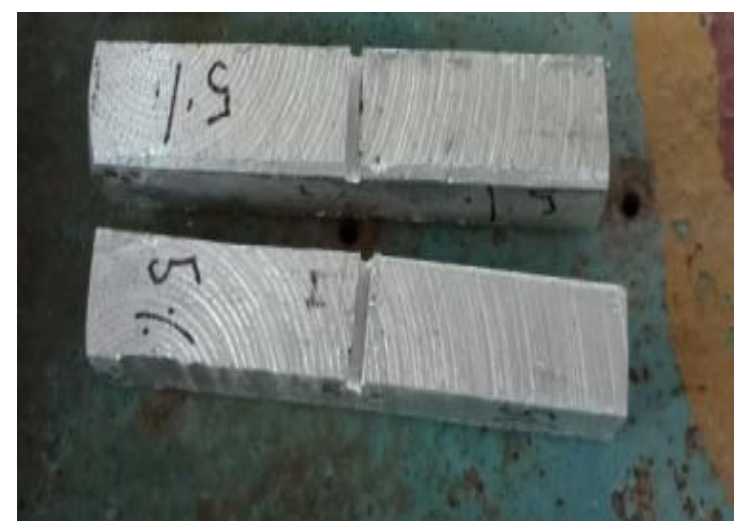

Figure 4: Specimens Prepared for Charpy test

Charpy impact test values have been calculated by using the following equaion (1). Then same procedure is followed with keeping the specimen in striking edge support and readings are taken[9]. Figure. 4 represents specimens prepared for charpy test.
Charpy Impact : K/A ........ Eqn. (1)

Where $\mathrm{A}$ is Area of cross-section $(\mathrm{A})=1 \mathrm{~cm} * 0.8 \mathrm{~cm}=0.8 \mathrm{~cm}^{2}$,

Fracture energy $(\mathrm{K})=\mathrm{K}_{1}-\mathrm{K}_{2}$,

Where $\mathrm{K}_{1}=$ Initial energy and

$\mathrm{K}_{2}=$ Final energy

\subsubsection{Bending Test}

The bend test is similar to the flexural test except the type of hardware and test techniques involved. Bend tests are used for ductile materials, while flexural tests are used for brittle materials [10]. Bending tests are led with the aid of putting a size of specimen over a vary and pushing down alongside the range to twist the material until failure. The dimension of the specimen to be bended was $100 \mathrm{~mm} * 30 \mathrm{~mm} * 3 \mathrm{~mm}$. The bend test may be performed by a test specimen named ASTM D790. The specimen must be cut into shape in accordance with the normal size of the ASTM D790 [11]. Figure.5 represents automated three point bending test machine.

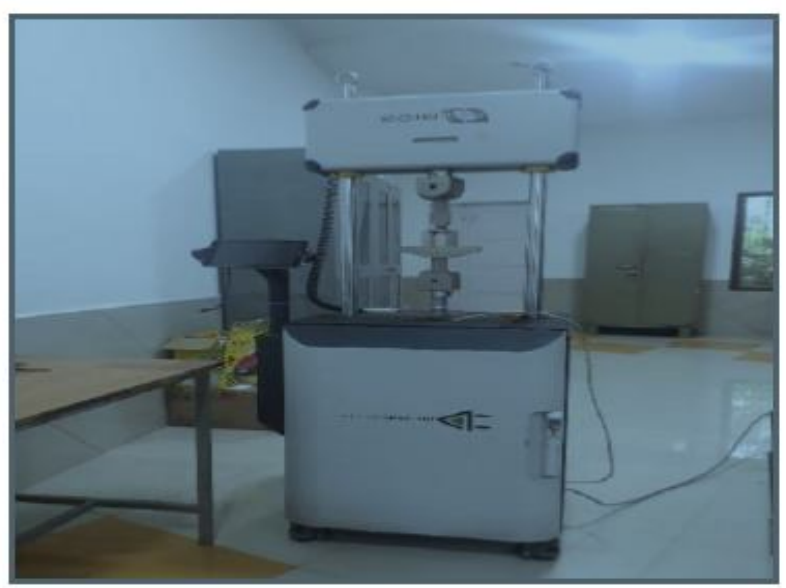

Figure 5: Automated Three point bending test machine

\section{Results and Discussions}

\subsection{Rockwell Hardness Test}

The test completed on the cast specimens yield following results: 
Table 2: Hardness values

\begin{tabular}{|c|c|c|}
\hline S. No & Composition & Hardness $\left(\mathrm{HR}_{\mathrm{B}}\right)$ \\
\hline 1 & Pure Aluminium & 55 \\
\hline 2 & $95 \% \mathrm{Al}$ and $5 \% \mathrm{~V}_{2} \mathrm{O}_{5}$ & 62 \\
\hline 3 & $90 \% \mathrm{Al}$ and $10 \% \mathrm{~V}_{2} \mathrm{O}_{5}$ & 67 \\
\hline
\end{tabular}

The values in the above table. 2 were noted down after the completion of the test in lab experimentally. There has been slight increase in the hardness of the component after addition of the $\mathrm{V}_{2} \mathrm{O}_{5}$ in increasing percentile.

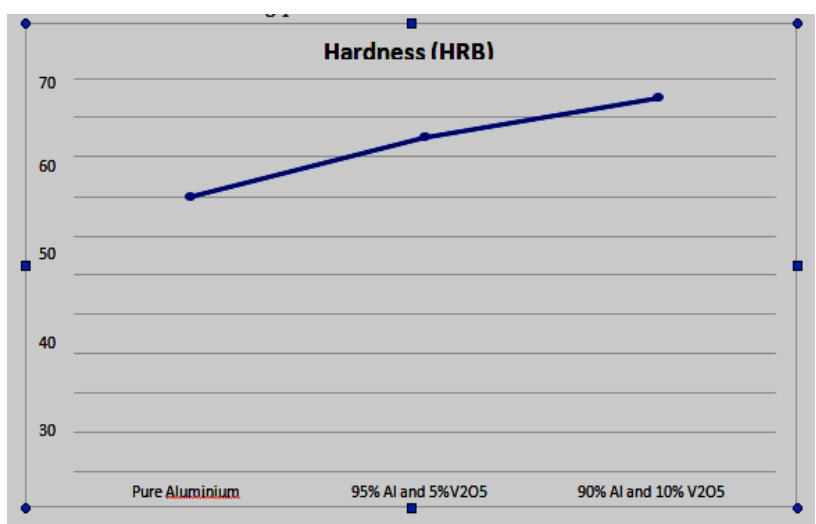

Figure 6: Variation of Hardness in $\mathrm{Al}$ with addition of $\mathrm{V}_{2} \mathrm{O}_{5}$ particulates

Inference: From the above graph(figure.6), it is obvious that the hardness of the composite increased on addition of $5 \mathrm{wt} . \%$ and $10 \mathrm{wt} . \%$ of $\mathrm{V}_{2} \mathrm{O}_{5}$ particulates. In the need of hard materials, this can be utilized as one of the means to get the same[12,13].

\subsection{Charpy Impact Test}

The specimens after Charpy Impact test gave the following details as shown in table.3:

Table 3: Charpy Impact Test Values

\begin{tabular}{|c|c|c|}
\hline S. No. & Composition & Impact $\left(\mathrm{J} / \mathrm{m}^{2}\right)$ \\
\hline 1 & Pure Aluminium & 0.45 \\
\hline 2 & $95 \% \mathrm{Al}$ and $5 \% \mathrm{~V}_{2} \mathrm{O}_{5}$ & 1.8 \\
\hline 3 & $90 \% \mathrm{Al}$ and $10 \% \mathrm{~V}_{2} \mathrm{O}_{5}$ & 2.3 \\
\hline
\end{tabular}

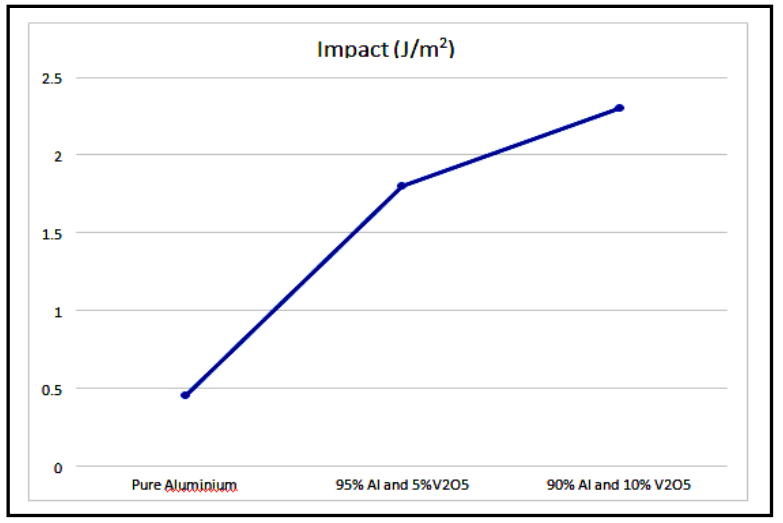

Figure 7: Charpy Impact Test values of $\mathrm{Al}$ with $\mathrm{V}_{2} \mathrm{O}_{5}$ prior and after addition

Inference: From above graph(figure.7), it is evident that impact value for pure Aluminium is negligible. On the other hand, with addition of $5 \mathrm{wt} \%$ and $10 \mathrm{wt} \% \mathrm{~V}_{2} \mathrm{O} 5$ particulates, the impact strength increased drastically[14,16].

\subsection{Bending Test}

Bending test performed on the specimens yield following results as shown in Table.4:

Table 4: Bending stress values of the specimens

\begin{tabular}{|c|c|c|}
\hline S. No. & Composition & $\begin{array}{c}\text { Bending } \\
\left.\text { stress(N/m }{ }^{2}\right)\end{array}$ \\
\hline 1 & Pure Aluminium & 127 \\
\hline 2 & $95 \% \mathrm{Al}$ and 5\%V2O5 & 245 \\
\hline 3 & $90 \% \mathrm{Al}$ and $10 \% \mathrm{~V} 2 \mathrm{O} 5$ & 380 \\
\hline
\end{tabular}

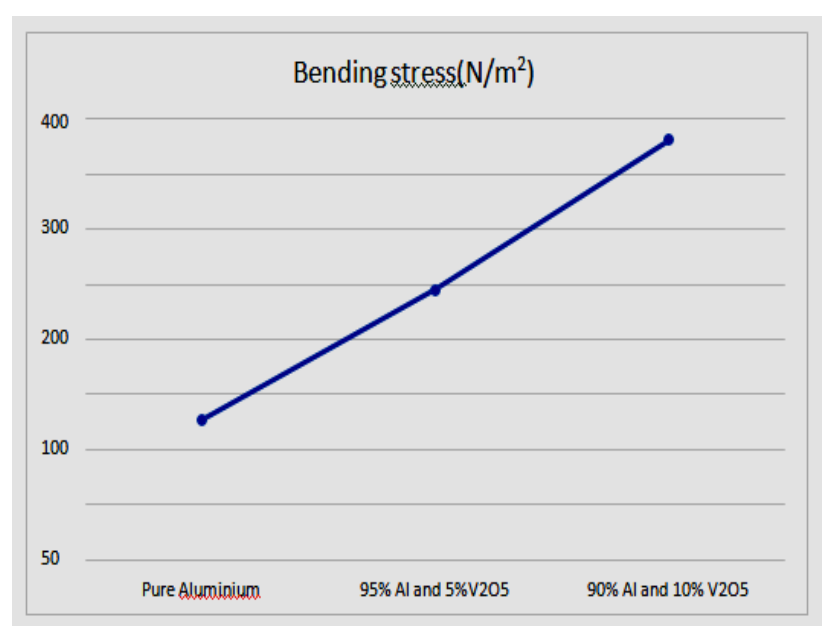

Figure 8: Variation in Bending stress value of $\mathrm{Al}$ with 
T. Vijaya Kumar et al., International Journal of Emerging Trends in Engineering Research, 8(10), October 2020, 7111 - 7115

\section{$\mathrm{V}_{2} \mathrm{O}_{5}$ prior and after addition}

Inference: From above graph(figure.8), it is clear that bending stress value for aluminium on addition of $5 \mathrm{wt} \%$ and $10 \mathrm{wt} \%$ increased drastically[15,17].

\section{CONCLUSIONS}

The metal matrix composites can be effectively produced using Stir casting technique. With Rockwell hardness tester, hardness of three specimens was found out and it is clear that composites having $5 \mathrm{wt} \%$ and $10 \mathrm{wt} \%$ of $\mathrm{V}_{2} \mathrm{O}_{5}$ has higher hardness when compared to pure Aluminum. A development in the proportion of help in the main network can be viewed as enhancing the entire properties of the material in line of mechanical aspect. The impact strength of pure Aluminum was found out to be almost negligible but on inclusion of $\mathrm{V}_{2} \mathrm{O}_{5}$ by $5 \mathrm{wt} \%$ and $10 \mathrm{wt} \%$ increased to certain level. Further, the bending stress value of pure $\mathrm{Al}$ was comparatively lesser than the values obtained on adding $5 \mathrm{wt} \%$ and $10 \mathrm{wt} \%$ of $\mathrm{V}_{2} \mathrm{O}_{5}$. Hence, using $\mathrm{V}_{2} \mathrm{O}_{5}$ as reinforcement was found to enhance the mechanical properties of pure Aluminium.

\section{REFERENCES}

[1] S. Mathivanan et.al, "Experimental Investigation on Aluminum Metal Matrix Composite", International Journal of Engineering Research \& Technology, ISSN: 2278-0181(2018)

[2] Ganesh J.V.S., et.al,'Experimental investigation on stir cast aluminium with aluminium oxide powders",International Journal of Mechanical and Production Engineering Research and Development, 8(3), PP.81-88(2018)

[3] Sundeep, D; Kumar, TV; Rao, PSS; Ravikumar, RVSSN; Krishna, AG, "Green synthesis and characterization of $\mathrm{Ag}$ nanoparticles from Mangifera indica leaves for dental restoration and antibacterial applications", Progress in Biomaterials, May (2017),DOI: 10.1007/s40204-017-0067-9.

[4] Basha, SKS; Rao, MC," Effect of annealing temperature on structural and morphological studies of electrodeposited CZTS thin films", Ceramics International, $\quad \operatorname{Jan}(2018), \quad$ DOI: 10.1016/j.ceramint.2017.09.224.

[5] Sundeep, D; et.al, "Spectral characterization of mechanically synthesized $\mathrm{MoO}_{3}-\mathrm{CuO}$ nanocomposite", International Nanoletters, JUN (2017), DOI: 10.1007/s40089-015-0178-z.

[6] Sundeep, Dola; et.al" Mechanical Milling Influence on Lattice Vibrational Behaviour of $\mathrm{MoO}_{3}$ $\mathrm{V}_{2} \mathrm{O}_{5}$ Composite Nanopowders", Silicon Publishers, JUNE(2019),DOI: 10.1007/s12633-018-9972-3.

[7] Rao, Thella Babu," An Experimental Investigation on Mechanical and Wear Properties of Al7075/SiCp Composites: Effect of SiC Content and Particle Size", Journal of Tribology -Transaction of ASME, May(2018), DOI: 10.1115/1.4037845.

[8] Vijaya Kumar.T et.al.,"Spectroscopic characterization of mechanically synthesized $\mathrm{MoO}_{3} / \mathrm{TiO}_{2} \quad$ composite nanopowders", IJMET,8(5),PP.1051-1063(2017).

[9] Sreenivasulu S., et.al.,"Comparisons of machining parameters in electro discharge machining of aluminium 6082 and hybrid NANO metal matrix composite",IJMET,8(5),PP.784-790(2017).

[10] Ramsudeesh $\mathrm{T}$ et.al, "Sintering of iron powder mixtures and determining their mechanical properties", IJMPERD ,Transtellar publishers, Vol.8, Issue:3, PP. 59-66(2018).

[11] Vijaya Kumar. $\mathrm{T}$ et.al.,'Experimental investigation on mechanical properties of palmyra long fibre reinforced composites', IJITEE, 8(7), PP.2046-2053 (2019).

[12] G. Jayashankar, et.al, "Effect of Rolling on Hardness of Aluminium Metal Matrix CompositesAn Experimental Study", IJMET, Vol.8, Issue 5, pp.525-530 (2017).

[13] Sai Krishna.B et.al, "Effect of Rolling on Microstructure of Aluminium Metal Matrix Composites with Magnesium Particulates-An Experimental Study", IJMET, Vol.8, Issue 5, pp.583587 (2017).

[14] Rao P.K.V., RaghuKumar B., Veera Sai Chandh Y., Teja A., 'Finite element analysis of CNT reinforced aluminium composite subjected to mechanical loading', Materials Today: Proceedings(2019).

[15] Ramana K.V. et.al.," An effect of ball milling on microstructural parametes of nanostructured $\mathrm{MoO}_{3}-\mathrm{CuO}-\mathrm{V}_{2} \mathrm{O}_{5}$ composite nanopowders", IJMPERD, Vol.9,issue.3(2019.)

[16] Jagadale V.S., Padhi S.N., 'Mechanical behavior of coir fiber reinforced polymer resin composites with saturated ash particles', International Journal of Innovative Technology and Exploring Engineering, 9(1), PP.3531-3535(2019).

[17] Rao.T.B, et.al.,"Microstructural and mechanical properties characterization of Al6061/nanoTICPcomposites fabricated through stircasting',IJMET,9(5),PP.193-199(2018). 